\title{
In vitro simulation of the gastrointestinal tract environment and its interaction with probiotic lactobacilli
}

\author{
Ayla Ilyazova ${ }^{1}$, Denica Blazheva $^{1 *}$, Aleksandar Slavchev ${ }^{1}$, and Albert Krastanov ${ }^{2}$ \\ ${ }^{1}$ Department of Microbiology, University of Food Technologies, Plovdiv, Bulgaria \\ ${ }^{2}$ Department of Biotechnology, University of Food Technologies, Plovdiv, Bulgaria
}

\begin{abstract}
The harshest conditions of the human gastrointestinal tract were simulated in order to study probiotic bacteria in their intended environment. Eight Lactobacillus strains were cultivated in MRS broth with added bile in different concentrations and their growth was monitored as optical density. The gathered data was used to determine the MIC of bile for each strain. The recovery of the strains in MRS broth after $3 \mathrm{~h}$ in simulated gastric juice solution $\left(\mathrm{pH} 1.8,5000 \mathrm{U} / \mathrm{cm}^{3}\right.$ pepsin) was investigated. Lactobacillus gasseri $\mathrm{S} 20$ exhibited the best survival rate and reached OD 600 0,490, while Lactobacillus acidophilus S11 could not survive the conditions of the stomach (OD 600 0,076).
\end{abstract}

\section{Introduction}

In 2001 the World Health Organization (WHO) and the Food and Agriculture Organization defined the definition of probiotics as "live microorganisms that, when administered in adequate amounts, confer a health benefit on the host" [1]. Later the International Scientific Association of Probiotics and Prebiotics (ISAPP) issued a position statement summarizing 7 minimum criteria that should be met for a microorganism to be legitimately called a "probiotic" food or supplement [2].

The first criterion requires characterization of the isolated strain, which is sufficient to identify it to the genus, species and strain level [2]. Apart from the precise identification of the microorganism, the characterisation is interpreted to include investigation of the properties, supporting the potential probiotic activity [3]. Such studies could include survival within the host organism, the production of beneficial substances, adhesion to mucus or intestinal epithelial cells, resistance to digestive enzymes, bile or acid, antibacterial activity, etc. [3].

Many studies have reported that the most commonly used probiotic bacteria - representatives of Lactobacillus and Bifidobacterium, exhibited natural susceptibility towards the harsh conditions of the gastrointestinal tract $[4,5,6,7]$. The highly acidic condition in the stomach, the presence of pepsin and the high ionic strength could be lethal to most microorganisms $[8,9]$. In the small intestines they are subjected to the activity of bile acids, which acting as detergents have the ability to damage cell membranes and DNA [10,11].

The aim of this study is to assess the ability of 8 Lactobacillus strains to survive an in vitro simulation of the conditions in the gastrointestinal tract as part of the selection process of potential probiotics.

\section{Materials and methods}

\subsection{Microorganisms}

Eight probiotic strains from genus Lactobacillus were used: Lactobacillus acidophilus S11, Lactobacillus delbrueckii subsp. bulgaricus $\mathrm{S} 2$, Lactobacillus delbrueckii subsp. bulgaricus $\mathrm{S} 4$, Lactobacillus delbrueckii subsp. bulgaricus S6, Lactobacillus delbrueckii subsp. bulgaricus S19, Lactobacillus delbrueckii subsp. bulgaricus S28, Lactobacillus gasseri S20 and Lactobacillus helveticus S3. The strains were isolated from fresh homemade cheese and yogurt. All microorganisms were cultivated in MRS broth (Oxoid, UK) and stored as $15 \%(\mathrm{w} / \mathrm{v})$ glycerol stock cultures at $30^{\circ} \mathrm{C}$.

\subsection{Preparation of active bacterial culture}

Active bacterial cultures were prepared by inoculation of $1 \mathrm{ml}$ MRS broth (Oxoid, UK) with $50 \mu 1$ glycerol stock culture, which were cultivated at $37^{\circ} \mathrm{C}$ until they reach optical density of 1 at $\lambda=600 \mathrm{~nm}$ [12].

\subsection{Determination of the optical density of the bacterial cultures}

The optical density was determined by using a micro-plate reader Spectrostar Nano (BMG LABTECH, Germany) against MRS broth as blank at $\lambda=600 \mathrm{~nm}$. The sample volume was $200 \mu \mathrm{l}$ with correction to $1 \mathrm{~cm}$ path length. Every value is presented as the mean of nine measurements (three samples, measured three consecutive times each) [13].

\footnotetext{
* Corresponding author: $\underline{\mathrm{d} \text { blazheva } @ \text { uft-plovdiv.bg }}$
} 


\subsection{Determination of the resistance to low $\mathrm{pH}$ value in presence of pepsin}

A modified method of Pitino [14] was used. Samples of $750 \mu \mathrm{l}$ MRS broth were inoculated with $50 \mu \mathrm{l}$ of active bacterial culture and cultivated for $18-20 \mathrm{~h}$ at $37^{\circ} \mathrm{C}$. The culture medium was then centrifuged at $10000 \mathrm{~min}^{-1}$ for 5 min, the biomass was washed twice with PBS buffer ( $\mathrm{pH}$ 7.00). The cells were suspended to the original volume with a low $\mathrm{pH}$ buffer ( $\mathrm{pH} 1.80)$, containing $\mathrm{HCl}(0.2 \mathrm{M})$, $\mathrm{NaCl}(0.08 \mathrm{M}), \mathrm{CaCl}_{2}(0.03 \mathrm{mM})$, and pepsin from porcine gastric mucosa $(9000 \mathrm{U} / \mathrm{ml})$ (Wako, Japan). After $3 \mathrm{~h}$ incubation at $37^{\circ} \mathrm{C}$ the biomass was centrifuged at $10000 \mathrm{~min}^{-1}$ for $5 \mathrm{~min}$, washed with PBS buffer and resuspended to its original volume with PBS buffer. Tubes containing $750 \mu \mathrm{l}$ MRS broth were inoculated with $50 \mu \mathrm{l}$ of treated cell suspensions and cultivated at $37^{\circ} \mathrm{C}$ for 24 $\mathrm{h}$. The optical density of the cultures was measured at $\lambda=$ $600 \mathrm{~nm}$ at $0 \mathrm{~h}$ and $24 \mathrm{~h}$. The strains' resistance to low $\mathrm{pH}$ in the presence of pepsin was evaluated by cell growth and presented by the increase in the optical density of the culture medium after $24 \mathrm{~h}$ cultivation $37^{\circ} \mathrm{C}$ [12].

\subsection{Determination of bile minimal inhibitory concentration}

Samples of $750 \mu \mathrm{l}$ MRS broth with $5,000 \mathrm{mg} / \mathrm{ml}$ dry bile (Wako, Japan) were diluted in deep-well plates by making serial twofold dilutions until a concentration of 0.156 $\mathrm{mg} / \mathrm{ml}$ dry bile was reached. Each well was inoculated with $50 \mu \mathrm{l}$ active bacterial culture and the trays were cultivated at $37^{\circ} \mathrm{C}$. The optical density at $\lambda=600 \mathrm{~nm}$ was determined after $24 \mathrm{~h}$.

\section{Results and discussion}

All probiotic microorganisms should be able to reach the lower parts of the digestive tract in sufficient numbers in order to fulfil their beneficial function. Therefore, our investigation started with a simulation of the conditions in the stomach and assessment of the ability of eight Lactobacillus strains to survive in the presence of the digestive enzyme pepsin at $\mathrm{pH} 1.8$ for $3 \mathrm{~h}$. After this period we removed them from this environment and placed them in MRS broth for $24 \mathrm{~h}$ in order to determine their viability.

The cells of Lactobacillus acidophilus S11 did not show signs of development after $24 \mathrm{~h}$ in favourable conditions (Fig. 1). Even the lowest pepsin concentrations prevented the microorganism from proliferation.

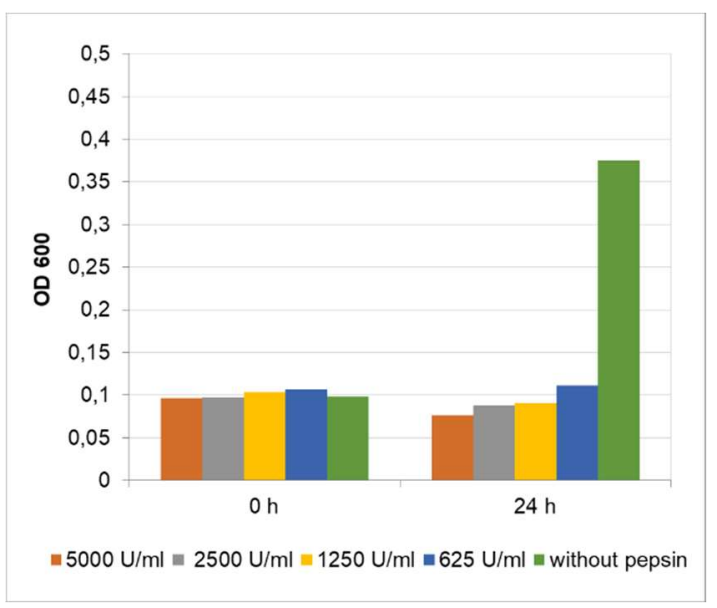

Fig. 1. Survival of Lactobacillus acidophilus $\mathrm{S} 11$ at $\mathrm{pH} 1.80$ in the presence of pepsin

The first representative of Lactobacillus bulgaricus Lactobacillus bulgaricus S2, also did not survive the simulated conditions of the stomach and only the control, which was not exposed to low $\mathrm{pH}$ and pepsin exhibited growth (Fig. 2).

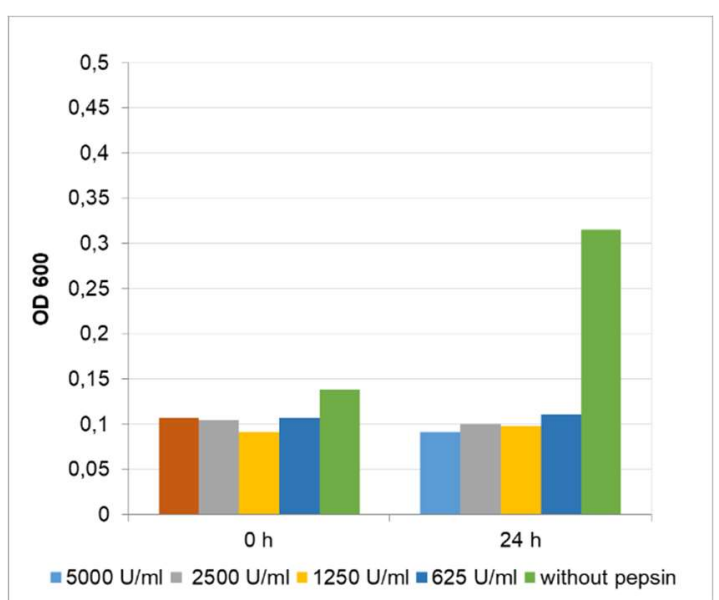

Fig. 2. Survival of Lactobacillus bulgaricus $\mathrm{S} 2$ at $\mathrm{pH} 1.80$ in the presence of pepsin

Both Lactobacillus bulgaricus S4 and L. bulgaricus S28 showed the same inability to overcome the negative effect of low $\mathrm{pH}$ in the presence of all of the tested pepsin concentrations as Lactobacillus bulgaricus S2 (Fig. 3 and Fig. 4). These results support the findings of other studies, that the representatives of Lactobacillus bulgaricus are very sensitive towards low $\mathrm{pH}$ values in the stomach $[15$, 16] 


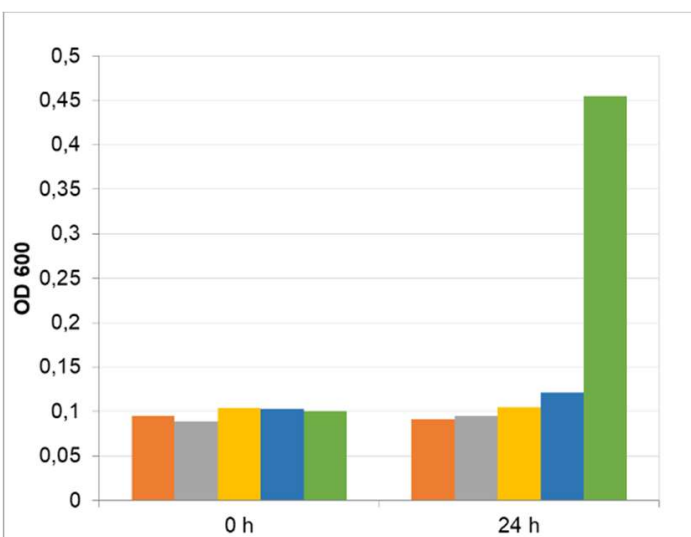

$=5000 \mathrm{U} / \mathrm{ml}=2500 \mathrm{U} / \mathrm{ml} \equiv 1250 \mathrm{U} / \mathrm{ml}=625 \mathrm{U} / \mathrm{ml} \equiv$ without pepsin

Fig. 3. Survival of Lactobacillus bulgaricus $\mathrm{S} 4$ at $\mathrm{pH} 1.80$ in the presence of pepsin

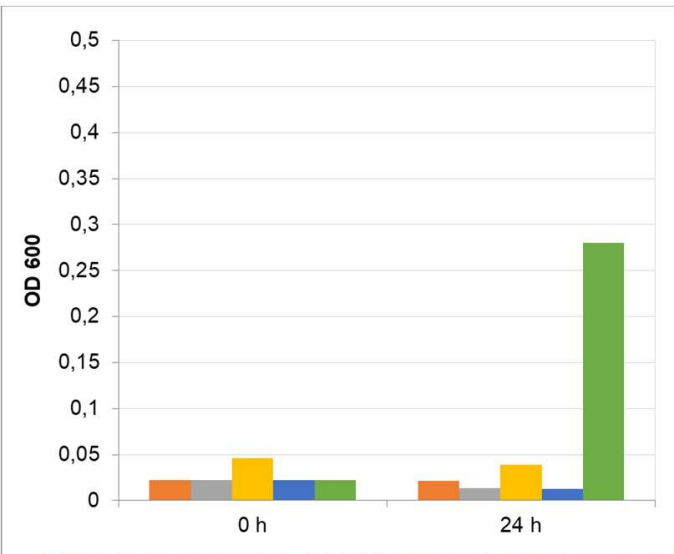

$=5000 \mathrm{U} / \mathrm{ml}=2500 \mathrm{U} / \mathrm{ml}=1250 \mathrm{U} / \mathrm{ml}=625 \mathrm{U} / \mathrm{ml}=$ without pepsin

Fig. 4. Survival of Lactobacillus bulgaricus $\mathrm{S} 28$ at $\mathrm{pH} 1.80$ in the presence of pepsin

On the other hand, some of the cells of $L$. bulgaricus S6 managed to survive the harsh conditions in pepsin concentrations from $625 \mathrm{U} / \mathrm{ml}$ to $2500 \mathrm{U} / \mathrm{ml}$. The increase in pepsin concentration led to fewer viable cells and at $5000 \mathrm{U} / \mathrm{ml}$ pepsin in combination with the low $\mathrm{pH}$ no significant change in the optical density was observed.

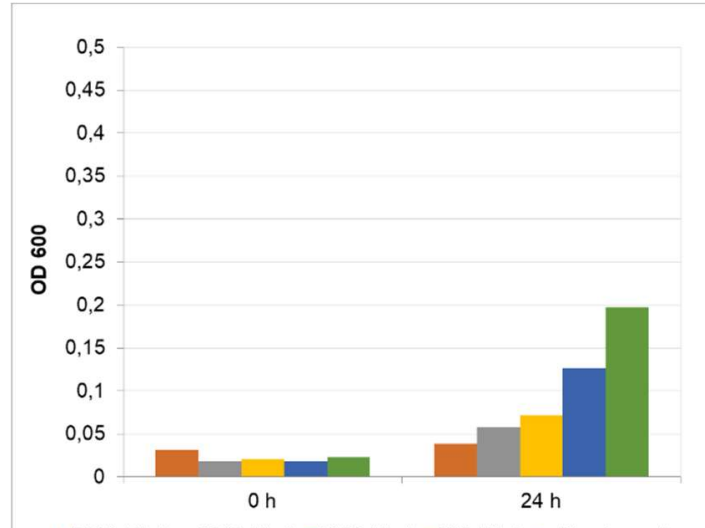

$=5000 \mathrm{U} / \mathrm{ml}=2500 \mathrm{U} / \mathrm{ml}=1250 \mathrm{U} / \mathrm{ml}=625 \mathrm{U} / \mathrm{ml}=$ without pepsin

Fig. 5. Survival of Lactobacillus bulgaricus $\mathrm{S} 6$ at $\mathrm{pH} 1.80$ in the presence of pepsin

To a greater extend the same correlation was observed in the Lactobacillus bulgaricus S19 culture (Fig. 6). The optical density of the suspensions exposed to all tested pepsin concentrations was comparable to that of the control. This strain showed the best survival rate of all Lactobacillus bulgaricus isolates.

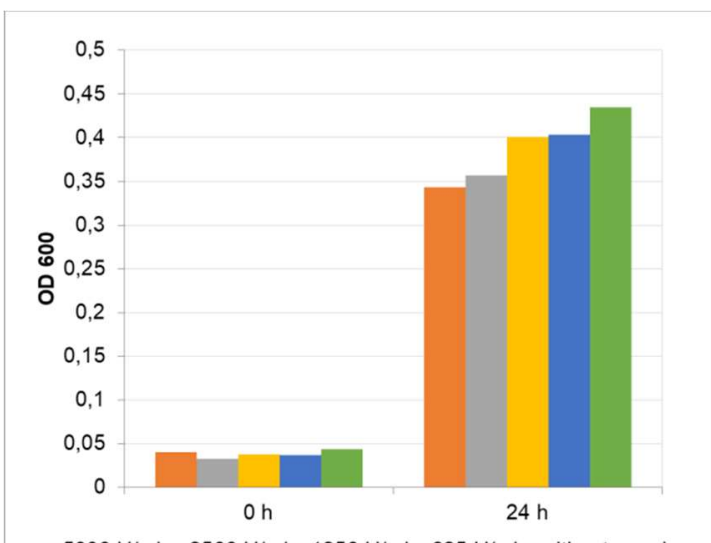

Fig. 6. Survival of Lactobacillus bulgaricus $\mathrm{S} 19$ at $\mathrm{pH} 1.80$ in the presence of pepsin

The most resistant strain overall was $L$. gasseri $\mathrm{S} 20$ (Fig. 7). Even at pepsin concentration $5000 \mathrm{U} / \mathrm{ml}$ it reached OD 6000.490 .

The last tested strain - Lactobacillus helveticus S3, exhibited similar results to Lactobacillus bulgaricus S6 (Fig. 8). Some cells survived the exposure to low $\mathrm{pH}$ and pepsin at all enzyme concentrations and the higher pepsin content caused more cellular damage.

All of the investigated strains were influenced by the low $\mathrm{pH}$ and the presence of pepsin to a different extent. The degree of reduction in viable cells (OD 600) was associated with the individual strains. Other authors report the same variation in resistance both between strains within one species and between different species of the genus Lactobacillus [6, 17-19].

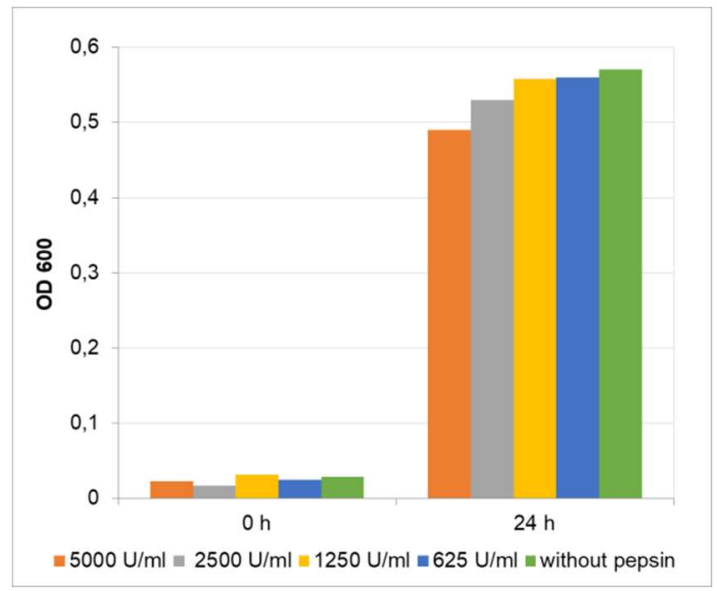

Fig. 7. Survival of Lactobacillus gasseri $\mathrm{S} 20$ at $\mathrm{pH} 1.80$ in the presence of pepsin 


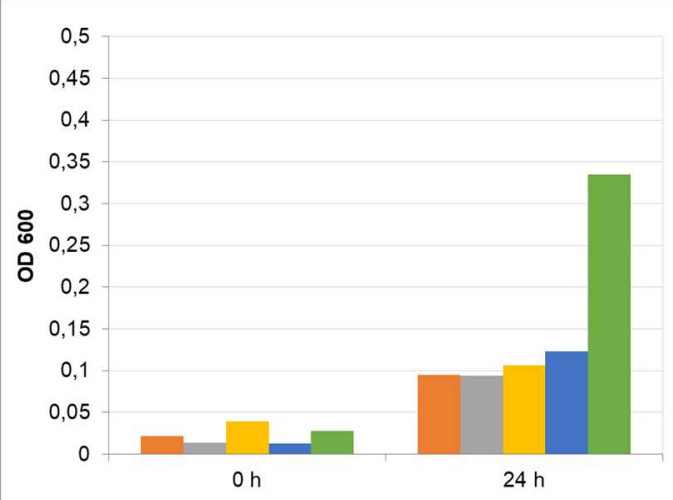

$\llbracket 5000 \mathrm{U} / \mathrm{ml}=2500 \mathrm{U} / \mathrm{ml}=1250 \mathrm{U} / \mathrm{ml}=625 \mathrm{U} / \mathrm{ml} \approx$ without pepsin

Fig. 8. Survival of Lactobacillus helveticus $\mathrm{S} 3$ at $\mathrm{pH} 1.8$ in the presence of pepsin

In the human body after the exposure to low $\mathrm{pH}$ and digestive enzymes the potential probiotics are subjected to high bile concentrations. In a series of experiments the studied Lactobacillus strains were assessed for bile resistance and the minimal inhibitory concentration (MIC) of bile for every strain was determined (Table 1). The results show that the most resistant strain was Lactobacillus gasseri S20 with MIC of bile $2.5 \mu \mathrm{g} / \mathrm{ml}$ (Fig. 9; Table 1). No growth was observed at this concentration and the higher tested concentrations $2 \mathrm{~h}$ after the beginning of the experiment. Bile concentration $1.25 \mu \mathrm{g} / \mathrm{ml}$ led to minimal growth. Further decrease in bile concentration improved the development of the strain and $0,313 \mu \mathrm{g} / \mathrm{ml}$ had practically no effect. The rest of the lactobacilli could be divided in two groups: a more sensitive group, comprised of Lactobacillus bulgaricus S6, Lactobacillus bulgaricus S19, Lactobacillus bulgaricus $\mathrm{S} 28$ and Lactobacillus helveticus S3, and a less sensitive one, including L. acidophilus S11, Lactobacillus bulgaricus S2 and Lactobacillus bulgaricus S4. In order to differentiate the strains within the groups the data for the optical density at sublethal concentrations of bile $(0.5$ MIC) is presented in Table 1.

Table 1. Bile minimal inhibitory concentrations

\begin{tabular}{|l|c|c|}
\hline Strain & MIC, $\boldsymbol{\mu g} / \mathbf{m l}$ & OD at $\mathbf{0 . 5}$ MIC \\
\hline L. acidophilus $\mathbf{S 1 1}$ & 1.250 & 0.520 \\
\hline L. bulgaricus $\mathbf{S 2}$ & 1.250 & 0.600 \\
\hline L. bulgaricus $\mathbf{S 4}$ & 1.250 & 0.605 \\
\hline L. bulgaricus $\mathbf{S 6}$ & 0.625 & 0.512 \\
\hline L. bulgaricus $\mathbf{S 1 9}$ & 0.625 & 0.628 \\
\hline L. bulgaricus $\mathbf{S 2 8}$ & 0.625 & 0.535 \\
\hline L. gasseri $\mathbf{S 2 0}$ & 2.500 & 0.313 \\
\hline L. helveticus $\mathbf{S 3}$ & 0.625 & 0.548 \\
\hline
\end{tabular}

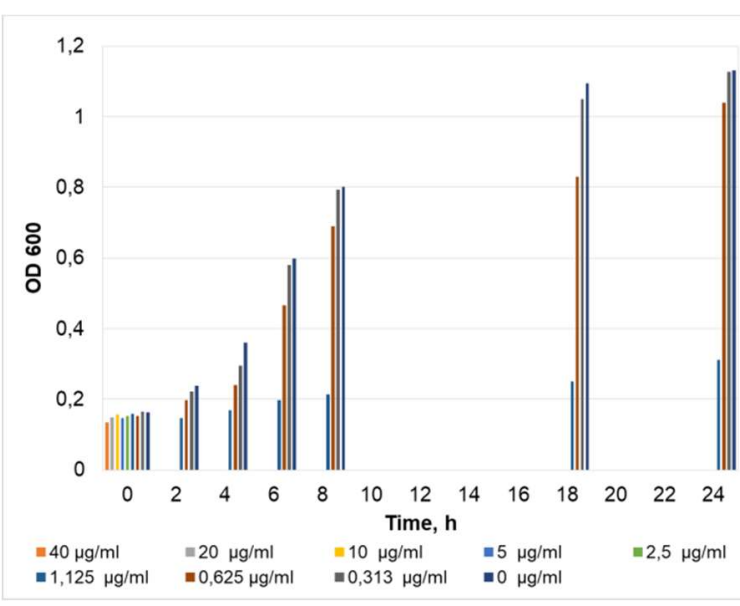

Fig. 9. Effect of bile on the growth and development of Lactobacillus gasseri S20

In the more resistant group Lactobacillus acidophilus S11 exhibited a slightly lower optical density, while the Lactobacillus bulgaricus strains reached OD 600 of 0.600. In the other group Lactobacillus bulgaricus S19 clearly showed less sensitivity than the rest of the lactobacilli.

Similar to the susceptibility to the simulated conditions of the stomach, the sensitivity of the strains towards bile varies from strain to strain even within one species which is in agreement with the results of other authors $[16,19]$.

\section{Conclusion}

The investigation of the resistance of eight Lactobacillus strains to simulated conditions of the human gastrointestinal tract showed their varied sensitivity towards low $\mathrm{pH}$ in the presence of pepsin and to bile. Lactobacillus gasseri S20 exhibited the greatest resistance and reached optical density of 0.490 at $\lambda=600$ $\mathrm{nm}$ after $3 \mathrm{~h}$ exposure to $\mathrm{pH} 1.80$ in the presence of 5000 $\mathrm{U} / \mathrm{ml}$ pepsin. The determined minimal inhibitory concentration of bile was $2.5 \mu \mathrm{g} / \mathrm{ml}$.

Acknowledgements: This work was supported by the Bulgarian Ministry of Education and Science under the National Research Programme "Healthy Foods for a Strong BioEconomy and Quality of Life" approved by DCM \# 577/ 17.08.2018.

\section{References}

1. FAO/WHO, Guidelines for the evaluation of probiotics in food (FAO, Paris, 2002)

2. ISAPP, Minimum criteria for probiotics [online]. (International Scientific Association for Probiotics and Prebiotics, Sacramento, CA, 2018)

3. S. Binda, C. Hill, E. Johansen, D. Obis, B. Pot, M. E. Sanders, A. Tremblay, A. C. Ouwehand, Frot. Microbiol. 11, 1662 (2020)

4. M. T. Cook, G. Tzortzis, D. Charalampopoulos, V. V. Khutoryanskiy, J. Control. Rel. 162, 56-67 (2012) 
5. C.C. Dodoo, J. Wang, A. W. Basit, P. Stapleton, S. Gaisford, Int. J. Pharm. 530, 224-229 (2017)

6. W.P. Charteris, P.M. Kelly, L. Morelli, J.K. Collins, J. Appl. Microbiol. 84, 759-768 (1998)

7. L. K. Sarao, M. Arora, Crit. Rev. Food Sci. Nutr. 57, 344-371 (2017)

8. I. Surono, J. Verhoeven, S. Verbruggen, K.Venema, J. Appl. Microbiol. 124, 1604-1609 (2018)

9. C. Gonzalez-Ferrero, J. M. Irache, C. J. GonzalezNavarro, Food Chem. 239, 879-888 (2018)

10. S. Hamner, K. McInnerney, K. Williamson, M. J. Franklin, T. E. Ford, PLoS One. 8, e74647 (2013)

11. M. Yao, J. Wu, B. Li, X. Hang, D. J. McClements, L. LI, Food Hydrocoll., 72, 228-236 (2017)

12. A. Slavchev, Z. Kovacs, H. Koshiba, A. Nagai, G. Bázár, A. Karstanov, Y. Kubota, R. Tsenkova, PLoS One. 10, e0130698 (2015)

13. A. Slavchev, Z. Kovacs, H. Koshiba, G. Bázár, B. Pollner, A. Krastanov, R. Tsenkova, J. Near Infr. Spectrosc. 25, 423-431 (2017)

14. I. Pitino, C.L. Randazzo, G. Mandalari, A. Lo Curto, R. M. Faulks, Y. Le Marc, C. Bisignano, C. Caggia, M. Sean J. Wickham, Food Microbiol. 27, 1121-1127 (2010)

15. S. Lindwall, R. Fonde, IDF Bulletin 179, 21(1984)

16. P.L. Conway, S.L. Gorbach, B.R. Goldin, J. Dairy Sci. 70, 1-12 (1987)

17. V. Chandramouli, K. Kailasapathy, P. Peiris, M. Jones, J. Microbiol. Meth. 56, 27-35 (2004)

18. W. K. Ding, N. P. Shah, J. Food Sci. 74, M53-M61 (2009)

19. L.-S. Chou, B.Weimer, J. Dairy Sci. 80, 23-31 (1999) 